\title{
O Perfil Dialógico como critério de avaliação na formação online de professores-tutores
}

\author{
Priscila Barros David* \\ Raquel Santiago Freire** \\ Paula Patrícia Barbosa Ventura***
}

\section{Resumo}

Este artigo analisa a relação entre a disposição para o diálogo e o índice de aproveitamento de professores-tutores participantes de um curso de formaçáo ofertado na modalidade educacional a distância. A pesquisa teve como objetivo investigar a inclusão dos pilares do diálogo freireano como critérios adicionais dentro do sistema de avaliação da aprendizagem do curso, viabilizando a realização de avaliaçôes formativas. O estudo constou de duas etapas gerais: a transformação dos pilares do diálogo em critérios de avaliação e a aplicação dos mesmos na avaliação da aprendizagem dos alunos. O agrupamento desses critérios denominou-se Perfil Dialógico, construído com base no referencial teórico de Paulo Freire e em estudos empíricos nele fundamentados, os quais analisam processos interativos em cursos nessa modalidade. A investigação contou com a participação de 29 professores-tutores em formação e o tutor-formador. O Perfil Dialógico permitiu observar as açôes dos estudantes em todas as atividades do curso, considerando, principalmente, as relaçôes por eles desenvolvidas. Os resultados apontam um alinhamento entre a primazia por contextos dialógicos e um aproveitamento satisfatório em cursos online voltados para a formação de professores.

Palavras-chave: Formação de Professores. Avaliação da Aprendizagem. Educação a Distância.

\footnotetext{
* Doutora em Educação pela Universidade Federal do Ceará (UFC). Professora do Instituto UFC Virtual e do Curso de Sistemas e Mídias Digitais na Universidade Federal do Ceará (UFC).

** Doutora em Educação pela Universidade Federal do Ceará (UFC). Professora do Instituto UFC Virtual e do Curso de Sistemas e Mídias Digitais na Universidade Federal do Ceará (UFC).

*** Mestre em Educação pela Universidade Federal do Ceará (UFC). Professora e Assessora Pedagógica da Faculdade Integrada da Grande Fortaleza.
} 


\section{Introdução}

Entre os processos que levam à obtenção dos padrôes de qualidade definidos como necessários dentro dos sistemas educacionais, a avaliação da aprendizagem constitui um aspecto central e de grande complexidade. Seu propósito é tentar compreender o progresso do aluno em termos de novos conhecimentos levando em conta, dentre outras coisas, os procedimentos didáticos por meio dos recursos pedagógicos empregados e a metodologia de ensino-aprendizagem do curso.

Luckesi (2008) apresenta três formas importantes para se acompanhar o desenvolvimento da aprendizagem: medição dos resultados da aprendizagem; transformação da medida em nota ou conceito; e utilização dos resultados identificados. $\mathrm{O}$ autor afirma que, historicamente, há uma predominância na adoção dos dois primeiros procedimentos, sendo o terceiro quase sempre desconsiderado. $\mathrm{Ou}$ seja, normalmente os dados coletados na avaliação da aprendizagem dos estudantes não são utilizados para revelar o que deve ser melhorado na didática dos professores ou mesmo o que deve ser feito para que os estudantes elaborem os conhecimentos mínimos esperados. $\mathrm{O}$ uso de instrumentos de avaliação da aprendizagem tem cumprido o propósito de apenas aferir para validar as conquistas intelectuais dos estudantes, conferindo-lhes o status de aprovado, reprovado, ou, no máximo, um convite à realização de novos testes/provas, de forma a alcançarem a média mínima para a aprovação.

$\mathrm{Na}$ área de Educação a Distância $(\mathrm{EaD})$, as práticas de avaliação também têm se utilizado de instrumentos para a verificação quantitativa da aprendizagem, fundamentadas em uma concepção mecanicista ou tradicional de avaliaçáo. Segundo Caldeira (2004), o processo de avaliação na $\mathrm{EaD}$ ainda é restrito à quantificação de participaçôes, acessos ao Ambiente Virtual de Aprendizagem (AVA) e à realização de provas objetivas, como testes de múltipla escolha, que irão representar o aproveitamento do aluno ao final do curso. Haydt (2002) denomina este procedimento de avaliaçáo somativa, que visa classificar os alunos de acordo com seus níveis de aproveitamento no processo de ensino-aprendizagem. Existe ainda uma segunda classe dentro das funções da avaliação: a avaliação diagnóstica. Esse tipo de avaliação compreende a identificação dos conhecimentos prévios dos alunos em determinada área, observando a existência dos requisitos básicos (conceitos, habilidades) necessários às novas aprendizagens, e é realizada no início do curso tendo em vista, dentre outras coisas, estimar possíveis problemas de aprendizagem e suas causas (HAYDT, 2002).

Ao longo dos anos, os AVA's vêm sendo aperfeiçoados, passando a incorporar diversas ferramentas que ampliam as possibilidades avaliativas do aprendizado de 
estudantes. Recursos como portfólios, fóruns de discussão, chat, entre outros, viabilizam a postagem de produçóes intelectuais dos alunos, o registro das interaçóes entre eles, bem como as intervençóes do professor, estendendo o universo de estratégias avaliativas passivas de serem implementadas em formaçóes online (OTSUKA; ROCHA, 2002; SCHLEMMER, 2005). O uso dessas ferramentas favorece a avaliação formativa (HAYDT, 2002), que orienta a prática pedagógica a identificar aspectos relevantes à aprendizagem do aluno, auxiliando-o a superar dificuldades. Polak (2009) defende que a avaliação na $\mathrm{EaD}$ precisa seguir abordagens processuais que valorizem os alunos enquanto sujeitos do processo. Para a autora, é preciso que a metodologia de um curso a distância contemple os conhecimentos construídos por meio das ferramentas de comunicação e interação.

Estudos têm demonstrado uma preocupação atual em se adotar procedimentos avaliativos formativos (BASSANI; BEHAR, 2006; DAVID et al., 2007; PRETI, 2008; OLIVEIRA, 2012), que contemplem as participaçôes dos estudantes durante todo o percurso de aprendizagem, seguindo critérios variados, tais como: a quantidade e o conteúdo das mensagens trocadas, a pontualidade na postagem das atividades, a qualidade da escrita etc. Esses estudos sobre avaliação em AVA reconhecem a importância da avaliaçáo formativa, enfocando, não somente aspectos quantitativos (número de acessos ao ambiente ou determinada atividade, quantidade de trabalhos enviados, dentre outros), mas também qualitativos (análise das interaçôes e conteúdo postados, mapeamento das contribuiçóes individuais e açôes de colaboração nas atividades propostas). Embora esses sejam critérios de avaliação importantes, percebese a necessidade de se observar as relaçóes entre os atores do processo educativo, a partir de paradigmas de educação que sejam apoiados em práticas dialógicas, como a pedagogia progressista de Paulo Freire (2006a).

O estudo aqui proposto tem como objetivo investigar a inclusão dos pilares do diálogo freireano como critério em sistemas de avaliação da aprendizagem voltados para cursos de formação online de professores-tutores. Dentro do sistema, este critério, denominado perfil dialógico, seria útil na análise da postura relacional do estudante frente aos demais participantes e seu tutor-formador. Busca-se identificar a relação entre as açôes dialógicas dos estudantes durante todo o processo de formação e seu rendimento no curso. A questão que norteou o trabalho foi: como critérios baseados na análise do perfil dialógico dos participantes se relacionam com o desenvolvimento satisfatório nas demais atividades do curso.

Inicialmente, neste artigo, será discutido o conceito de avaliação formativa na $\mathrm{EaD}$, cuja função se estende para além da simples constatação do nível de conhecimento do aluno (avaliação diagnóstica) ou mesmo da qualificação final de seu 
rendimento (avaliação somativa), mas prevê momentos de interação entre os atores da educação com o propósito de rever práticas que não estejam concorrendo para o real aprendizado dos estudantes. $\mathrm{Na}$ sequência, os pilares do diálogo freireano serão apresentados como possíveis critérios a serem incorporados em sistemas de avaliaçáo da aprendizagem. Em continuação, pesquisas sobre processos avaliativos fundamentados numa abordagem interacionista e dialógica serão discutidas, destacando-se suas lacunas para a literatura da área. Nesse contexto, o estudo proposto é descrito e os dados, analisados à luz do referencial teórico de Freire (2006a, 2006b) e de David (2010). Na conclusão, os resultados permitirão verificar a relação entre a avaliação do perfil dialógico do professor-tutor em formação e os resultados por ele obtidos no curso.

\section{A avaliação formativa na EaD}

A avaliação formativa pode ser entendida como toda prática de avaliação contínua que pretenda melhorar as aprendizagens em curso, contribuindo para o acompanhamento e orientaçáo dos estudantes durante todo o seu processo de formação. Segundo Perrenoud (1999, p. 78), "é formativa toda avaliação que ajuda o aluno a aprender e a se desenvolver, que participa da regulaçáo das aprendizagens e do desenvolvimento no sentido de um projeto educativo". Na visão de Hadji (2001, p. 25), que complementa a do primeiro autor, a avaliaçáo formativa é "capaz de orientar o trabalho dos professores no sentido de uma prática avaliativa colocada, tanto quanto possível, a serviço das aprendizagens".

Referenciada por Villarruel-Fuentes (2003) como avaliação com base no processo, a avaliação formativa possui um propósito regulador, permitindo a reorientação do processo educacional, mediante uma análise constante dos conhecimentos dos estudantes. Tem como objetivo identificar possíveis dificuldades que possam estar incidindo no aprendizado, sem precisar esperar pelo encerramento do curso. A avaliação com base no processo busca compreender não somente o que se ensina e o que se aprende como também sob que circunstâncias se ensina e se aprende (contexto). A avaliação formativa é aplicada durante todo o processo, funcionando como um feedback das conquistas intelectuais dos alunos e das fragilidades da metodologia. Contribui, assim, para a realização de possíveis ajustes ao planejamento do ensino, tendo em vista o alcance dos objetivos de aprendizagem.

Cerny e Ern (2001) apontam a avaliação formativa como um processo de comunicação entre estudantes e professores na $\mathrm{EaD}$, na qual estudantes podem demonstrar o que e como aprenderam, revelando as dificuldades encontradas no percurso e, os professores, a oportunidade de rever e repensar metodologias aplicadas. 
Numa perspectiva formativa, a avaliação passa a fazer parte do próprio processo de ensino-aprendizagem, sendo incluída como uma atividade contínua que cumpre o papel de iluminar as açóes pedagógicas e de aprendizado dos atores envolvidos (estudantes e professores). Both (2005) argumenta que a avaliação e o ensino devem manter simultaneidade e concomitância de ação, de intervenção e de efeito. Isso significa uma interaçáo constante entre educador e educandos por meio da qual seja possível estabelecer reflexôes sobre conteúdos e metodologias adotados, como também sobre avanços e dificuldades na trajetória de aprendizagem.

Ao discutir a metodologia da avaliação-ensino (ensinar avaliando e avaliar ensinando), Both (2005, p. 57) argumenta que:

[...] o papel do educador poderá passar mais facilmente da questáo ainda muito presente de "sabe tudo" para a de "provocador" de situaçôes de conflito, de demonstrador das diferentes realidades, de apontador de novos horizontes, incentivando o educando à co-responsabilidade quanto ao desenvolvimento sócio-pessoal.

Por essa razão, abordagens tradicionais, behavioristas, de mera transmissão de conhecimentos não se coadunam com a perspectiva da avaliação formativa. Em geral, nesse tipo de abordagem o processo avaliativo é generalista. Questóes padronizadas são dirigidas a todos os alunos, ao mesmo tempo, e sob as mesmas condiçōes, prevalecendo a concepção de que as aprendizagens acontecem igualmente para todos. A avaliação cumpre, assim, o papel de testar conhecimentos que foram ministrados sob condiçóes especiais, de forma que todos, ao final do processo, consigam reproduzir as mesmas respostas.

Para a efetivação do modelo da avaliação-ensino, argumentado por Both (2005), é requerido do professor uma mudança de postura frente a modelos pedagógicos tradicionalmente efetivados, de simples validaçáo dos conhecimentos dos estudantes. Para avaliar de maneira formativa, o professor precisa nortear suas açóes pedagógicas por uma abordagem dialógica e sociointeracionista. Isso inclui o compartilhamento das açóes do processo avaliativo com os estudantes, construindo critérios claros em colaboração com eles, passando a utilizar sistemas de avaliação que possibilitem todo o registro de evolução dos conhecimentos desses estudantes. Logo, percebe-se uma redefinição dos papéis, onde o aprendiz é um parceiro, assumindo a responsabilidade pelo seu desempenho e acompanhando a própria aprendizagem.

Barbosa (2008) argumenta em favor da avaliação como processo interativo, em que haja um procedimento contínuo de investigaçáo sobre os conhecimentos, 
habilidades e atitudes dos estudantes e professores, favorecendo que qualquer tomada de decisão sobre o planejamento avaliativo seja uma decisão coletiva sobre as aprendizagens e açôes em curso. Trata-se de um tipo de avaliaçáo mais democrática na qual a responsabilidade pelo diagnóstico do desempenho não está somente nas mãos do professor, mas também do próprio aluno, na medida em que é convidado a perceber se seus conhecimentos estão alinhados com os objetivos propostos.

Cerny e Ern (2001) apresentam outros argumentos para a implementação de avaliaçóes formativas na $\mathrm{EaD}$, com base em pesquisas sobre avaliação da aprendizagem. Segundo os autores, os estudantes aprendem melhor quando são avaliados por meio de atividades que relacionam o contexto do curso com situaçôes vivenciadas em seu cotidiano. Além disso, eles esperam obter retornos rápidos e significativos de seu desempenho de tal sorte que possam rever alguma inconsistência e obtenham melhores resultados. O estudante deseja ainda sentir-se parte do processo educacional contribuindo não somente com o seu aprendizado individual, mas também coletivo, dos pares e do próprio professor.

Para que a avaliação formativa na $\mathrm{EaD}$ seja viabilizada é relevante que a informação coletada por meio dos instrumentos (fóruns, chats, portfólios etc.) seja organizada de forma acessível para os alunos e compartilhada dentro de um contexto que estimule o diálogo entre eles e seus professores. Um processo avaliativo desta natureza pode se dar de maneira individual ou coletiva, considerando dados produzidos pelo próprio aluno, pelo professor e até mesmo pelos pares.

O estudo aqui proposto, a ser detalhado mais adiante, apresenta uma sistematização da avaliação formativa com base nos pilares do diálogo freireano. Os resultados dessa avaliaçáo serão relacionados com o nível de aproveitamento obtido pelos participantes de uma formaçáo de professores-tutores ofertada na modalidade a distância.

$\mathrm{Na}$ próxima seção, discutiremos as contribuiçôes da abordagem dialógica freireana como um importante referencial teórico para nortear a realização de avaliaçôes formativas em cursos a distância.

\section{Contribuições da abordagem dialógica freireana para a avaliação formativa}

Em sua vasta obra, Paulo Freire trouxe contribuiçóes relevantes para açóes educacionais de modo geral. Embora não tenha discutido especificamente a questáo da avaliação da aprendizagem, este teórico fez consideraçóes importantes sobre a avaliação como instrumento de emancipaçấo e transformação da realidade dos educandos. Ao 
pesquisar as aproximaçóes entre a obra de Paulo Freire e a teoria da avaliação da aprendizagem, Cupolillo (2007) faz uso do conceito de diálogo para refletir sobre as contribuiçôes da avaliação formativa ao desenvolvimento de uma consciência crítica dentro do processo educacional.

O diálogo para Freire (2006a) é um instrumento de libertação, sendo definido dentro de uma linha ideológica e política. A educação dialógica freireana se opóe à concepção educacional bancária, de simples transferência de conhecimentos, e valoriza a participação autônoma dos estudantes na construção de seus percursos de aprendizagem. O diálogo freireano possui cinco pressupostos que norteiam a comunicação educador-educando: amor, humildade, fé nos homens, esperança e um pensar crítico. Esses elementos estão na base de uma educação dialógica e problematizadora sendo de grande relevância para a reflexão em torno da avaliaçáo formativa.

De acordo com Cupolillo (2007, p. 60), "o processo avaliativo deve distanciarse de seu viés punitivo e castrador das diferenças". Tal perspectiva representa o que Freire (2006a) denomina querer bem aos educandos como algo que dá sentido à prática educativa. Na visão de Freire (2006a), um ambiente favorável à produção do conhecimento desmistifica o medo criado em torno da figura do professor, na medida em que o aluno se sente a vontade para se expressar livremente sem julgamentos ou censura. Assim, em contextos de formação humana, é importante que o conhecimento seja trabalhado dentro de uma perspectiva relacional, de confiança e respeito mútuo, no qual as diferenças são respeitadas, os ritmos de elaboração de saberes também, além da capacidade criadora dos estudantes. Nesse sentido, os temores criados em torno da figura do professor são desmistificados, uma vez que esta abordagem aproxima-o dos estudantes, favorecendo suas intervençôes durante os percursos de aprendizagem.

Freire (2008) também critica a perspectiva mensuradora e controladora da avaliação. Para ele, a riqueza do processo educativo está na valorização da heterogeneidade dos sujeitos. Defende que a rigidez relacionada ao tempo e ao modo de aprendizagem seja desfeita em procedimentos avaliativos contribuindo com a perspectiva da avaliaçáo formativa na medida em que valoriza a diversidade de interesses e açóes dos sujeitos.

Ainda refletindo sobre as consideraçôes de Paulo Freire quanto a procedimentos avaliativos formativos, Cupolillo (2007) destaca a relevância de se construir uma relação democrática educador-educando, livre do autoritarismo e do uso abusivo de poder, comumente empregados em processo avaliativos. Essa relação democrática encontra-se pautada no segundo princípio do diálogo freireano: a humildade. Trata-se de um convite à reflexáo coletiva em torno do objeto de conhecimento, que pode ter 
início em exposiçôes feitas pelo professor, mas que não se finda nas mesmas, antes instiga a participação dos estudantes a também contribuírem com o aprendizado coletivo. De acordo com Freire (2006b, p. 120), "Enquanto relaçáo democrática, o diálogo é a possibilidade de que disponho de, abrindo-me ao pensar dos outros, não fenecer no isolamento".

Nessa perspectiva, se o ato de conhecer é dialógico e o conhecimento uma construção dinâmica e coletiva, a avaliação envolve, igualmente, um aspecto dinâmico, coletivo e, necessariamente, compartilhado entre os sujeitos. Freire (1982) sugere que assim como o ato pedagógico, os procedimentos avaliativos sejam compartilhados entre professores e estudantes. Segundo o autor, "A avaliação é da prática educativa e não dum pedaço dela. O educando também deve participar da avaliaçáo da prática, porque o educando é um sujeito dessa prática. A não ser que nós o tomemos como objeto da nossa prática" (FREIRE, 1982, p. 94).

Rios (2006) considera que o diálogo estabelecido entre avaliador e avaliado, isto é, professor e estudante, favorece o desenvolvimento da cultura da avaliação formativa por permitir que o sujeito avaliado torne-se consciente do seu próprio desenvolvimento. Assim, a autora defende a participação do avaliado, desenvolvendo a autoavaliação e a autorregulação, para que o processo ganhe contornos de negociação e sentimentos de humildade, especialmente entre os educadores.

Portanto, a ação dialógica oferece grandes possibilidades de superação das perspectivas unilaterais e determinantes da avaliaçấo. Ao colocar em confronto diversas formas de apreensão e apropriaçáo do conhecimento, amplia as possibilidades de se conhecer o outro e a si mesmo, permitindo, assim, o desenvolvimento e a utilizaçáo de metodologias cada vez mais adequadas à diversidade do cotidiano.

De acordo com Freire (2006a, p.93), o diálogo também envolve fé nos homens: "fé no seu poder de fazer e de refazer. De criar e recriar. Fé na sua vocação de ser mais, que não é privilégio de alguns eleitos, mas direito dos homens". Isto representa a capacidade do ser humano de aprender sempre, de crescer, de desenvolver-se no contato com o outro. É o que Freire (2007) denomina educabilidade.

O professor movido por fé nos homens reconhece e valoriza a autonomia, a criatividade e a inquietude de seus estudantes. Compreende-o como um ser inconcluso que se encontra em um movimento constante de busca por novos conhecimentos. Cria, portanto, um ambiente problematizador, propondo situaçôes que incentivem os estudantes à participaçáo. Estes, por sua vez, passam a compartilhar suas experiências autonomamente, resolvem problemas em conjunto e vivenciam momentos de crescimento e aprendizado constante. 
Ao criticar a Pedagogia por Objetivos, uma forma de avaliação tradicional, de definição de comportamentos a serem atingidos e posterior mensuração desses comportamentos, Cupolillo (2007) retoma o conceito de inacabamento (inconclusão), desenvolvido por Freire (2007, p. 61): "O professor, ao saber-se inacabado, como qualquer ser humano, disponibiliza-se ao inacabamento do outro (aluno), participando com mais tolerância e respeito dos processos de construçáo de conhecimento de si e dos alunos".

Nesse sentido, há que se questionar as evidências afirmadas nos processos avaliativos, ao rotularem como fracassados os alunos que não se apropriam do conteúdo escolar sequenciado e no tempo fixado pelo professor. Numa aproximaçáo com a concepção dialógica freireana, a avaliação formativa compreende que as apropriaçóes (pelos alunos) dos conhecimentos esperados não podem ser rígidas, mas reconstruídas a partir das leituras heterogêneas dos diversos sujeitos engajados em processos de aprendizagem.

A inconclusão ou inacabamento do ser, de acordo com Freire (2007), envolve uma tomada de consciência deste estado que o mobiliza a superá-lo por meio do que o autor denomina curiosidade epistemológica. Tal curiosidade é caracterizada como um processo pessoal e social de busca por conhecimento, que envolve mais do que conteúdos, mas uma ampla reflexão sobre a realidade.

Essa abordagem educacional contempla a valorização de diferentes habilidades construídas individual e coletivamente pelos estudantes. Criticidade, autonomia e criatividade tornam-se variáveis importantes a serem contempladas nos processos avaliativos, que não podem ter como característica a universalidade. Logo, o processo de avaliação da aprendizagem alinhado com a abordagem educacional dialógica precisa se revestir de um caráter dinâmico, personalizado, negociado e compartilhado entre todos os atores nele engajados. É o caso, por exemplo, de se fazer uso de variados instrumentos de coleta de dados de forma a congregar registros de diferentes momentos do percurso de aprendizagem, e de se levar em conta o olhar avaliativo do professor, do próprio aluno e dos pares, de tal sorte que diferentes pontos de vista sejam contemplados no diagnóstico dos conhecimentos em elaboração.

O diálogo freireano também está fundamentado na esperança. Na visão de Paulo Freire (2007), o isolamento e a desesperança levam o homem a um estado de estagnação, prejudicial ao seu desenvolvimento.

A esperança faz parte da natureza humana. Seria uma contradição se, inacabado e consciente do inacabamento, primeiro, o ser humano náo se inscrevesse ou náo se achasse predisposto a participar de um movimento constante de busca, 
e, segundo, se buscasse sem esperança... A esperança é uma espécie de ímpeto natural possível e necessário [...] é um condimento indispensável à experiência histórica. Sem ela, não haveria História [...].. (FREIRE, 2007, p. 72).

Logo, a esperança está relacionada a uma ação coletiva que irá favorecer o processo de humanizaçáo, de autoafirmação do ser humano e de criação de sua própria história. É no processo educacional que contextos favoráveis a esta criação emergem, por meio do debate, da reflexáo coletiva e do diálogo, mobilizando as pessoas ao crescimento, à mudança e à transformação.

A disponibilidade ao diálogo apresenta-se, então, como uma condição indispensável à educação problematizadora, crítica e construtiva. Dialogar é abrir-se à compreensão do outro e deixar-se conhecer pelo outro, para que, juntos, atinjam patamares mais elevados de leitura e entendimento do mundo. A consciência do inacabamento, como discutido anteriormente, é um condimento que mobiliza educadores e educandos à busca por respostas às suas inquietaçôes, gerando aprendizado coletivo.

Esta ação coletiva representa o nível de complexidade da avaliação formativa dentro do processo ensino-aprendizagem. De acordo com Perrenoud (1999), não existe avaliação sem avaliador nem avaliado, ao mesmo tempo, não existe avaliação sem relação social e sem comunicação (inter)pessoal. A valorização de processos interativos na avaliaçáo formativa possibilita ao avaliador promover o crescimento dos estudantes em múltiplas dimensôes, para além da conteudista.

Assim, a avaliação assume uma dimensão orientadora, colaborativa e interativa, onde os resultados obtidos no decorrer do trabalho conjunto entre professor e estudantes são comparados com os objetivos propostos, a fim de constatar progressos, dificuldades, além de reorientar o trabalho docente na construção dos projetos pedagógicos. A presença de esperança dentro do processo avaliativo pode ser sentida na medida em que os resultados deste processo estimulam os estudantes à mudança, ao crescimento, ao interesse pelo aprofundamento de seus conhecimentos. Este sentimento só pode ser desenvolvido dentro de uma relação de confiança mútua, de alegria e prazer pela atividade educativa que perpassa os encontros estabelecidos entre educadores e educandos, no diálogo gerador e resultante do diagnóstico produzido pela avaliação.

Como último pilar da educação dialógica, Freire (2007, p. 32) aponta o pensar crítico: "Uma das tarefas precípuas da prática educativo-progressista é exatamente o desenvolvimento da curiosidade crítica, insatisfeita, indócil”. Esta abordagem rompe 
com concepçóes pedagógicas em que o aluno age como um receptor passivo de conhecimentos. O saber é concebido numa perspectiva dinâmica, em constante transformação, e depende de uma visão totalizada do contexto. Freire (2008) menciona um impeto criador, inerente ao ser humano, que precisa ser levado em conta nas açôes de conscientização e desenvolvimento da leitura crítica do mundo. Este conhecimento move os indivíduos em formação a se posicionarem criticamente no contato com diferentes posiçôes sobre determinado tema. Nesse sentido, deve-se fomentar a habilidade argumentativa dos estudantes, excluindo-se toda e qualquer prática restritiva e punitiva do processo educacional.

Muitos acham que o aluno deve repetir o que o professor diz na classe. Isso significa tomar o sujeito como instrumento. O desenvolvimento de uma consciência crítica que permite ao homem transformar a realidade se faz cada vez mais urgente. $\mathrm{Na}$ medida em que os homens, dentro de sua sociedade, vão respondendo aos desafios do mundo, vão temporalizando os espaços geográficos e vão fazendo história pela sua própria atividade criadora. (FREIRE, 2008, p, 32).

A constituição do pensamento crítico na abordagem dialógica freireana alinhase com uma perspectiva de avaliação da aprendizagem para a formação dos indivíduos, não para sua castração ou inibição. $\mathrm{O}$ autor, portanto, defende a adoção da avaliação formativa que substitui a visão autoritária do professor e de uso abusivo de poder por uma visão dialógica, de proximidade com os estudantes, que prioriza o aprofundamento dos conhecimentos e a problematização do mundo, com vistas à construção de uma consciência crítica. Uma avaliação de cunho verificacionista e de validação não é compatível com esta abordagem, não valoriza e nem permite a expressão da diversidade de pensamento. Ou seja, caminhará sempre em direção contrária à tomada de consciência como processo de aquisiçấo da autonomia e do movimento de transformação dos indivíduos em formação.

Rios (2006) compartilha desta concepção defendendo o exercício da metacogniçáa dentro do processo de avaliação formativa. Segundo a autora, a metacogniçấo desencadeia questionamentos ou investigaçáo sobre um aspecto que o próprio estudante considera que necessita ser mudado. Trata-se de um elemento fundamental para a implementação de inovaçôes pedagógicas e está, portanto, ligado a uma postura crítica do estudante que alimenta o desenvolvimento pessoal e coletivo.

Nesta seção, o diálogo freireano foi apresentando como fundamento teórico para a realização de avaliaçóes formativas. A construção de um cenário propício ao aprendizado faz-se necessária para a constituição de um contexto pautado na 
participação de todos os envolvidos no processo educacional. A seguir, serão discutidas algumas pesquisas que ressaltam a preocupação de estudiosos com o desenvolvimento de procedimentos avaliativos dentro de uma perspectiva progressista de educação.

\section{Pesquisas sobre avaliação formativa na educação a distância}

Sob diferentes enfoques, pesquisas vêm sendo realizadas sobre a temática da avaliação da aprendizagem em cursos ministrados na modalidade a distância (OTSUKA; ROCHA, 2002; DAVID et al., 2007). Neste artigo, pretende-se destacar as pesquisas de Bassani e Behar (2006), Preti (2008) e Oliveira (2012) pela proximidade com o objetivo do presente estudo.

Bassani e Behar (2006) discutem uma proposta metodológica para a avaliação da aprendizagem em AVA, a partir das interaçôes individuais e interindividuais em um curso a distância. O modelo apresentado envolveu a análise das interaçóes em disciplinas dos cursos de graduação e pós-graduação da Universidade Federal do Rio Grande do Sul (UFRGS), durante o primeiro semestre de 2005. Os dados foram coletados por meio da ferramenta interROODA, considerando os registros armazenados na base de dados do ambiente ROODA (Rede Cooperativa de Aprendizagem).

Baseado na concepção construtivista-interacionista de Piaget (1973), o modelo contempla aspectos qualitativos e quantitativos, envolvendo interaçóes sujeitoambiente virtual de aprendizagem-sujeito e ferramenta-sujeito-disciplina. $\mathrm{O}$ aspecto qualitativo prevê a visualização do conteúdo, o mapeamento das contribuiçóes individuais dos participantes e sua interconexão com as contribuiçôes de outros participantes. No aspecto quantitativo, é possível verificar a quantidade de acessos ao ambiente, o número de trabalhos enviados e a frequência de participação em determinada ferramenta de interação.

Ao viabilizar diferentes olhares sobre os dados coletados dentro do AVA, a pesquisa de Bassani e Behar (2006) corrobora com o modelo de avaliação defendido neste artigo (avaliação formativa), discutindo a avaliação da aprendizagem no plano interindividual. As autoras pontuam que as interaçóes entre pares sejam analisadas integrando-se três critérios: o conteúdo da mensagem, o valor da troca e o tipo de mensagem. Tais critérios são capazes de subsidiar a avaliação da aprendizagem em ambientes online ao levarem em conta tanto o olhar do professor quanto dos demais alunos, desconstruindo hierarquias e incluindo a participação de todos os atores no ato educacional. 
Dados qualitativos oriundos da análise do conteúdo das mensagens possibilitam evidenciar o aprofundamento teórico, refletir sobre a dinâmica das interaçóes que se constituem entre os participantes e avaliar o percurso de aprendizagem do aluno de forma contextualizada, onde cada contribuição pode ser analisada não apenas pelo conteúdo, mas também pela integração com as demais mensagens. O valor da troca se constitui a partir do efeito que uma mensagem/contribuiçáo produz no grupo, sendo que quanto maior o número de mensagens vinculadas à mensagem original, maior o valor desta mensagem. O tipo da mensagem refere-se às características do texto postado, que pode ser um comentário, resposta, reflexão, pergunta ou outro. Assim como o conteúdo, o tipo de mensagem também pode estar relacionado à continuidade ou não de uma troca. Ainda que os critérios citados priorizem uma avaliação qualitativa de aprendizagem, Bassani e Behar (2006) destacam que eles podem ser vinculados a uma avaliação quantitativa, desde que um tipo de avaliação não se sobressaia sobre a outra.

Outro estudo que corrobora com a proposta deste artigo é o de Preti (2008). Com o objetivo de identificar as percepçóes que os tutores têm sobre sua atuaçáo no processo de avaliação da aprendizagem dos alunos, bem como analisar os registros por eles produzidos durante este processo, Preti (2008) apresenta reflexóes elaboradas durante a fase inicial de um estudo realizado junto aos tutores dos cursos de Licenciatura em Pedagogia e Bacharelado em Administração do Núcleo de Educação Aberta e a Distância (NEAD) da Universidade Federal de Mato Grosso (UFMT). Neste programa, os tutores trabalham em conjunto com um professor especialista da área, que é responsável pela oferta da disciplina. As reflexôes do autor tomam por base três aspectos relevantes no que tange à avaliação da aprendizagem: diferentes estratégias de avaliação; as condições e os critérios de avaliação.

No que concerne às estratégias de avaliação, Preti (2008) destaca como relevante um diálogo aberto entre professores especialistas, tutores e estudantes, em que possam discutir todas as atividades avaliativas: exercícios, sínteses, trabalhos individuais e de grupo, além de apresentaçóes e seminários. $\mathrm{O}$ autor ressalta também a importância da avaliaçâo entre pares, o que oportuniza a cada ator ser corresponsável pela aprendizagem mútua. Esta prática foi desenvolvida por meio da apresentação de trabalhos finais nas disciplinas mediante o parecer de colegas, tutores e do professor especialista. A terceira estratégia considerada por Preti (2008) consiste na autoavaliação, possibilitando identificar as dificuldades encontradas pelos tutores no processo avaliativo e uma reflexâo sobre o resultado das decisóes tomadas e dos caminhos percorridos.

Preti (2008) destaca ainda quatro condiçóes às quais o tutor deve se adequar para uma avaliação bem sucedida: domínio do conteúdo da disciplina que ele ministra; conhecimento da proposta de avaliação do curso; clareza acerca da fundamentaçáo 
teórica da avaliação a ser implementada; e levar em conta o contexto do aluno durante o seu acompanhamento no curso (perfil, situação socioeconômica etc.).

Náo obstante o preenchimento dessas condiçôes, o autor aponta que os tutores manifestaram dificuldades quanto à forma de avaliar, preocupando-se não apenas em atribuir uma nota, mas em saber se a avaliaçáo feita por eles estava condizente com os princípios estipulados pelo curso. Como forma de dirimir essa dificuldade, os especialistas sugerem critérios a serem utilizados pelos tutores na avaliaçáo do desempenho dos estudantes. Entre esses critérios estâo: a realização de todas as atividades do curso, a ampliação das leituras para além do material didático proposto, o levantamento de questóes e a compreensão crítica dos conceitos. A clareza nos critérios de avaliação é fundamental para que o professor tenha êxito na atividade de avaliar.

Em outra pesquisa, Oliveira (2012) desenvolve um estudo para investigar o processo avaliativo da aprendizagem, com base em critérios, por meio da análise de fóruns virtuais na $\mathrm{EaD}$. Toma como referência os conceitos de avaliaçáo formativa de Perrenoud (1999) e o de interatividade proposto por Silva (2006) e a partir destas bases teóricas, analisa quatro fóruns em quatro disciplinas (um fórum de cada disciplina com tutores diferentes) do curso Planejamento, Implementação e Gestão da EAD (PIGEAD). A análise focou na investigação da interação/intervençôes realizadas entre os participantes nos fóruns. Este curso foi desenvolvido entre os anos de 2010 e 2011 e ofertado pela Universidade Federal Fluminense (UFF), em convênio com a Universidade Aberta do Brasil (UAB).

Baseado nos dois conceitos referenciados anteriormente (avaliaçáo formativa e interatividade), Oliveira (2012) elencou critérios que pudessem ser observados como requisitos de avaliação da aprendizagem, sendo eles Informação, Participação e Intervenção, que, por sua vez, foram divididos em categorias menores. Para o critério Informaçâo, elencou-se a clareza na informação (tanto nos objetivos do fórum quanto no seu processo avaliativo); já no critério Participação, as subcategorias número de participaçóes, pertinência ao tema do fórum e contribuição. Por fim, para o critério Intervenção foram atribuídas as seguintes subcategorias: identificação de erros/desvios ao longo da discussão, sugestão quanto à estratégia/atitude dos alunos, realimentação da discussão com perguntas adicionais e problematização de uma ideia ou conteúdo.

A partir desses critérios, foi investigado até que ponto as postagens dos alunos, assim como as intervençóes dos tutores, as réplicas e tréplicas se pautavam em uma prática formativa e colaborativa. Convém destacar que a análise foi predominantemente qualitativa, embora fosse necessário estabelecer alguns indicadores para a quantidade de participaçóes e intervençôes, contados pelo número de ocorrências (de 0 a 4 e de 5 a mais ocorrências). Quando o indicador era um valor 
abstrato como clareza ou pertinência (náo podendo ser mensurado em termos de quantidade), utilizaram-se os mesmos indicadores numéricos para representá-los, ficando assim: 0 correspondente à ausência (de clareza, pertinência etc.); 1 ou 2 correspondente ao conceito de ruim; 3 ou 4 correspondente a bom; e 5 ou mais corresponde a ótimo.

Estabelecidos os critérios e realizada a análise, Oliveira (2012) destaca que os itens mais presentes foram a clareza nos objetivos e na avaliação dos fóruns, enquanto os mais ausentes dizem respeito à realimentação da discussáo com perguntas adicionais e à problematização de ideia ou conteúdo. O autor enfatiza também que estes dois aspectos

[...] sugerem que a atitude predominante ainda é a pedagogia da transmissão, onde os cursistas aguardam instruçóes do professor ou tutor e se contentam em respondê-las estritamente conforme o enunciado, sem se preocuparem em realimentar a discussão com conteúdos extras ou mesmo problematizar o tema. (OLIVEIRA, 2012, p. 9).

Ainda assim, se comparados aos dados de forma geral, o autor afirma que os resultados são favoráveis e positivos para a $\mathrm{EaD}$, faltando apenas implementar os critérios considerados mais ausentes na análise.

Os estudos abordados nesta seção representam iniciativas dos pesquisadores em desenvolver processos formativos de avaliação mediante a adoção de metodologias que considerem um diagnóstico mais condizente com a realidade do aluno, além de oferecer subsídios para a reorientação da didática aplicada no sentido de rever os procedimentos de ensino-aprendizagem.

Preti (2008) aponta estratégias, condiçôes e critérios de avaliação, construindo um universo amplo de parâmetros a serem observados na implementação de uma avaliação formativa, alinhada à perspectiva defendida neste artigo. Considerando os critérios sugeridos pelos especialistas aos tutores na avaliação das atividades, verifica-se ainda uma aproximação deste estudo com a concepção dialógica de Paulo Freire, ao destacarem a relevância dos alunos exercerem sua autonomia (esperança), ampliando as leituras para além dos materiais didáticos indicados, bem como o desenvolvimento do seu senso crítico (pensar crítico).

Preocupaçáo semelhante tiveram Bassani e Behar (2006) ao considerarem a importância de se evidenciar o aprofundamento teórico nas mensagens trocadas em fóruns de discussão em cursos a distância. As pesquisadoras identificaram também que mensagens contendo reflexôes e questionamentos geraram uma maior continuidade nas interaçóes, o que também aproxima a abordagem do curso investigado com uma 
visão progressista de avaliação, no que concerne ao princípio da esperança e do pensar crítico.

Contudo, percebe-se que tanto Bassani e Behar (2006) quanto Preti (2008) não ampliaram seu olhar investigativo para os outros pilares do diálogo destacados por Freire (2006a), ou seja, o amor, a humildade e a fé nos homens. O princípio do amor avaliaria o respeito mútuo entre os participantes e o desenvolvimento de relaçóes pautadas na ética e na confiança, o que favorece a construção de um ambiente favorável à produção do conhecimento. A humildade observaria o cuidado do aluno em não se colocar frente à turma como o detentor do saber, mas sim assumir uma postura de incentivar os colegas a contribuírem com o processo educativo. Já a fé nos homens atestaria a valorização mútua da autonomia, da criatividade e da curiosidade dos discentes, buscando criar um ambiente propício ao debate eà livre expressão.

Outro aspecto importante a ser considerado no estudo de Bassani e Behar (2006) foi o objeto de análise da investigação. A pesquisa deteve-se na análise específica do conteúdo das mensagens, no que concerne ao seu conteúdo, valor e tipo. Essa estratégia representa um avanço frente a outros modelos avaliativos, centrados exclusivamente em elementos quantitativos. Contudo, não houve uma preocupação em se observar a postura relacional dos participantes no processo interativo, fator este de extrema relevância, dentro da abordagem dialógica freireana.

Oliveira (2012) apresenta um olhar mais amplo nesta direção, ao abordar a necessidade de estabelecer critérios que foquem não apenas na informação, participação e intervençấo, mas na relação entre professor-tutor e aluno, tornando-a mais autônoma, dialógica, crítica e problematizadora. Mesmo sem usar o referencial teórico de Freire (2006a, 2006b), o autor observa a fé nos homens, a esperança e o pensar crítico em processos de avaliaçáo. A esperança corresponde ao engajamento dos participantes por um constante aprendizado (coletivo) possuindo um espírito científico, demonstrado pela realização de pesquisas, para além dos materiais didáticos do curso. Já o pensar crítico é visto a partir da reflexão feita sobre o próprio processo de aprendizagem como também dos colegas. Nas discussóes, os alunos argumentam e confrontam ideias, mostrando aprofundamento do que foi aprendido e a problematização voltada à construção de uma consciência crítica.

Por essa razão, entende-se a relevância de usar os pilares da educação dialógica como mais um critério a ser incorporado nos sistemas de avaliação de cursos a distância, numa tentativa de conferir uma abordagem mais ampla de avaliação que alinhe a perspectiva formativa com a abordagem dialógica freireana, como descrito na seção 2 deste artigo. 


\section{O estudo}

Este estudo tem por objetivo investigar a inclusão dos pilares do diálogo freireano no sistema de avaliação da aprendizagem do Curso de Formação Inicial de Tutores a Distância, ofertado em 2011 pela Universidade Federal do Ceará (UFC). O curso capacita professores-tutores de diferentes áreas para atuarem no Sistema Universidade Aberta do Brasil (UAB) nesta universidade. Possui uma carga-horária de 90 horas/aula, distribuídas em seis aulas, ministradas predominantemente a distância por meio da plataforma Solar1 (Ambiente Virtual de Aprendizagem da UFC).

A inclusão dos pilares do diálogo freireano foi baseada no Sistema de Análise de Interaçôes Contingentes (SAIC), resultado da tese de doutorado de David (2010), o qual contém elementos que concorrem para o desenvolvimento de avaliaçóes formativas em cursos a distância. O SAIC é composto por quatro categorias (Conversação, Textualização, Diálogo e Aprendizagem) e utiliza os pilares do diálogo freireano como critérios relevantes para a observação das relaçôes sociais construídas entre os participantes de cursos a distância (professores e estudantes), consistindo em elemento fundamental para que as interaçôes sejam propícias ao aprendizado. Inspirada no referencial teórico de Paulo Freire (2006a, 2006b, 2007), a categoria Diálogo do SAIC foi utilizada como fundamento para a construção do Perfil Dialógico, objetivo deste artigo.

O universo da pesquisa foi uma turma de 29 participantes composta por professores-tutores da área de Pedagogia. Este estudo descreve a relação entre a avaliação dos estudantes ao longo da formação e o Perfil Dialógico. A avaliação é feita a partir da análise progressiva das atividades realizadas ao longo do curso, que incluem a participação em encontros presenciais e em atividades desenvolvidas por meio da Plataforma (participação em fóruns de discussão, sessóes de chat e atividades postadas em portfólio). A cada atividade é atribuído um conjunto de escores os quais, somados aos escores do Perfil Dialógico (descrito na próxima seção), geram o resultado final da avaliação do professor-tutor em formação.

O objetivo deste estudo é investigar a relação entre o resultado final obtido pelos estudantes e sua avaliação no Perfil Dialógico, cuja construção será descrita a seguir.

\section{Construção do perfil dialógico}

O Perfil Dialógico do sistema de avaliação da aprendizagem em apreço foi desenvolvido em duas vertentes, isto é, contemplando um aspecto qualitativo e outro quantitativo de avaliação. 
Os critérios qualitativos do Perfil Dialógico correspondem aos pilares do diálogo freireano, conforme descritos a seguir:

- Afetividade (amor): quando o estudante preserva o respeito mútuo e a ética na construçáo de um ambiente favorável à produção do conhecimento e, na comunicação a distância, expressa cordialidade por meio de palavras ou recursos paralinguísticos (emoticons, sublinhados, marcadores etc.);

- Simetria Discursiva (humildade): quando o estudante náo se coloca frente à turma como detentor do saber e, nos debates, incentiva os colegas a contribuírem com o processo educativo;

- Valorização da Autonomia (fé nos homens): identificada por meio da valorização da autonomia dos colegas, buscando criar um ambiente propício ao debate e à livre expressão;

- Exercício da Autonomia (esperança): demonstra o engajamento na busca por um aprendizado (coletivo) e revela o espírito científico do estudante, demonstrado pela realização de pesquisas, para além dos materiais didáticos do curso;

- Reflexividade crítica (pensar crítico): quando há um forte processo de reflexão sobre o próprio processo de aprendizagem como também dos outros. Nos debates, argumenta, confronta ideias, problematiza.

Em cada um desses critérios qualitativos, o estudante poderia alcançar, por aula, de 0 a 2 escores. Uma vez que o curso era composto por seis aulas, ao final do mesmo, cada estudante poderia alcançar até 12 escores no Perfil Dialógico, do total de 100 escores obtidos nas atividades em geral.

Os critérios quantitativos do Perfil Dialógico foram assim distribuídos:

- 2 escores: em todas as atividades da aula o estudante contemplou todos os critérios qualitativos do Perfil Dialógico;

- 1,5 escores: em uma ou duas atividades da aula o estudante contemplou três ou quatro critérios do Perfil Dialógico;

- 1 escore: em uma ou duas atividades, contemplou um ou dois critérios do Perfil Dialógico;

- 0,5 escore: em apenas uma atividade contemplou um ou dois critérios do Perfil Dialógico;

- 0 escore: quando o estudante, em todas as atividades, não contemplou nenhum critério do Perfil Dialógico.

Os estudantes aprovados no curso obtiveram 70 ou mais escores na totalidade das atividades desenvolvidas, incluindo-se o Perfil Dialógico. Os que alcançaram menos 
de 50 escores ficaram reprovados. Aqueles que obtiveram entre 50 e 69 escores receberam a oportunidade de realizar uma atividade complementar para serem novamente avaliados. Os resultados desta pesquisa, descritos na seção Aplicação do perfil dialógico, buscam relacionar os escores obtidos nas atividades, em geral àqueles obtidos em relação ao Perfil Dialógico.

\section{Aplicação do perfil dialógico}

O sistema de avaliação aplicado nesta edição do Curso de Formação Inicial de Tutores a Distância foi apresentado aos participantes por ocasião do primeiro encontro presencial, tendo sido amplamente discutido e, depois, compartilhado em formato digital dentro da plataforma virtual de suporte ao curso. O Perfil Dialógico, elemento avaliativo inovador proposto para este curso a distância, foi descrito detalhadamente durante a aula, mediante a apresentação de exemplos, tendo em vista esclarecer o papel deste critério dentro do sistema de avaliação.

Também foram realizadas reuniōes regulares com o tutor-formador, paralelamente ao andamento do curso, ocasião em que os resultados do Perfil Dialógico eram discutidos e utilizados na implementação de medidas didáticas no sentido de alcançar melhores resultados de aprendizagem. Entre essas medidas, o tutor-formador mencionou o envio de mensagens gerais aos estudantes, informando os pontos de sua participação nas atividades do curso que necessitavam de mais engajamento. Quando o índice obtido no Perfil Dialógico era baixo em duas aulas seguidas, o tutor-formador passava a enviar mensagens privadas, concedendo-lhes recomendaçóes mais específicas. No que concerne às atividades de portfólio, ele sempre os estimulava a enviarem suas atividades antes da data final de postagem, de tal forma que pudessem receber comentários e realizar os devidos ajustes para o envio em definitivo.

Durante as reuniôes pedagógicas, o tutor-formador informou que as medidas didáticas tomadas com base nos índices do Perfil Dialógico, causaram um efeito positivo no desenvolvimento da autonomia e do senso crítico dos estudantes, além de resultarem em maior engajamento e espontaneidade de sua parte, como pode ser constatado nos resultados apresentados a seguir.

\section{Análise dos dados e resultados}

A Tabela 1 apresenta os escores totais obtidos pelos estudantes e os escores relacionados ao Perfil Dialógico. Os participantes estão ordenados de acordo com seu aproveitamento total no curso. Esta classificação foi proposta para facilitar a análise da relação entre o índice de aproveitamento nas atividades e os escores do Perfil Dialógico. 
Tabela 1 - Escores totais e escores do Perfil Dialógico por aluno

\begin{tabular}{ccc|ccc}
\hline Aluno & $\begin{array}{c}\text { Escores } \\
\text { obtidos } \\
\text { no curso }\end{array}$ & $\begin{array}{c}\text { Escores no } \\
\text { Perfil Dialógico }\end{array}$ & Aluno & $\begin{array}{c}\text { Escores } \\
\text { obtidos no } \\
\text { curso }\end{array}$ & $\begin{array}{c}\text { Escores no } \\
\text { Perfil Dialógico }\end{array}$ \\
\hline 01 & 95 & 12 & 16 & 74 & 7 \\
02 & 94 & 12 & 17 & 74 & 7 \\
03 & 92 & 11 & 18 & 74 & 7 \\
04 & 90 & 9 & 19 & 74 & 6 \\
05 & 90 & 9 & 20 & 72 & 5 \\
06 & 90 & 9 & 21 & 70 & 8 \\
07 & 87 & 10 & 22 & 70 & 7 \\
\hline 08 & 85 & 9 & 23 & 18 & 4 \\
09 & 85 & 9 & 24 & 13 & 3 \\
\hline 10 & 81 & 8 & 25 & 11 & 1 \\
11 & 81 & 8 & 26 & 9 & 1 \\
12 & 79 & 6 & 27 & 9 & 1 \\
13 & 78 & 8 & 28 & 5 & 1 \\
\hline 14 & 77 & 8 & 29 & 4 & 0 \\
15 & 77 & 8 & & & \\
\hline
\end{tabular}

Fonte: Elaboração das autoras.

Os resultados apontam que os nove primeiros estudantes alcançaram de 9 a 12 escores no Perfil Dialógico e, na avaliação total das atividades, obtiveram de 85 a 95 escores, sendo aprovados. Os treze estudantes seguintes alcançaram de 5 a 8 escores no Perfil Dialógico, obtendo como resultado de 70 a 81 escores na avaliação final. Estes, por sua vez, também foram aprovados. Assim, os estudantes que receberam bons ou medianos escores no Perfil Dialógico, tiveram bom êxito ao final do curso.

Os sete últimos estudantes, com Perfil Dialógico entre 0 e 4 escores e índices na avaliação das atividades entre 4 e 18 foram considerados desistentes, pois deixaram de participar das atividades geralmente depois da segunda aula. Por essa razão, não é possível afirmar se esses estudantes adotaram uma postura dialógica, uma vez que desistiram ainda no início da formação.

O Perfil Dialógico representa o contexto gerado pelas açóes dos estudantes no desenvolvimento das atividades propostas. Como já foi citado, aqueles que obtiveram um bom Perfil Dialógico lograram êxito ao final do curso, demonstrando que 
atentaram para a importância de não somente cumprir com as atividades, mas também para a qualidade de suas interaçôes, criando um cenário favorável à construção coletiva do conhecimentos. Esse resultado é respaldado pelo Sistema de Análise de Interaçóes Contingentes (SAIC), proposto no estudo de David (2010). Esse sistema aponta para a necessidade de se observar diferentes facetas da comunicação, entre elas o tipo de relaçáo desenvolvida pelos participantes de cursos a distância, para identificar o contexto mais propício ao aprendizado.

O sistema de avaliação proposto neste artigo observa as interaçóes que se constituem ao longo de um curso a distância voltado para a formação dos professorestutores de pedagogia da UFC. Estes foram avaliados a partir de aspectos quantitativos e qualitativos, os quais levaram em conta, dentre outras coisas, sua disposição para a prática do diálogo freireano. Assim como no trabalho de Bassani e Behar (2006), o enfoque quantitativo da interação faz referência ao que é possível analisar em termos de informações quantificáveis. No caso do trabalho de Bassani e Behar (2006), o aspecto quantitativo foi relacionado à quantidade de trabalhos enviados ou ainda ao número de contribuiçóes em uma determinada ferramenta. Neste estudo, a avaliaçáo quantitativa foi baseada em aspectos qualitativos de um perfil desejável dentro de uma proposta sociointeracionista e dialógica de interação, sendo utilizado pelo professor-tutor como referência para o desenvolvimento de uma avaliação formativa.

Assim, considera-se que implementar processos avaliativos que levem em conta os aspectos do diálogo, pode contribuir tanto para o desenvolvimento dos conhecimentos dos estudantes quanto para orientar a didática do professor responsável pelo seu acompanhamento. O Perfil Dialógico pode representar um indicador importante para a implementaçáo de açóes didáticas durante o curso, por refletir a postura do estudante frente às relaçóes desenvolvidas com seus pares e professor, além de retratar seu engajamento no desenvolvimento de habilidades centrais em qualquer processo educativo, e fundamentais no contexto de cursos a distância, tais como o senso crítico e a autonomia.

Os estudos apresentados na seção de pesquisas deste artigo apontam uma preocupação dos professores e gestores educacionais tanto em relação ao uso de critérios e estratégias variadas nos processos avaliativos, quanto à participação de diferentes atores responsáveis pelo diagnóstico do aproveitamento dos estudantes, seja o professor, ele próprio ou seus pares.

Contudo, considera-se que os mesmos foram limitados ao observarem apenas alguns aspectos do diálogo freireano e outros não, apontados por Freire (2006a) como fundamento da Educação Dialógica. Além disso, os estudiosos elencaram um universo muito amplo de aspectos a serem considerados na avaliação, como fez Preti (2008) ao 
destacar estratégias, condições e critérios de avaliação. Isso pode dificultar o trabalho do professor-tutor na identificação das razóes e do momento ideal, durante o curso, para a realização de intervençóes didáticas, tendo em vista o uso de medidas formativas de acompanhamento pedagógico.

Nesse sentido, o uso de parâmetros, dentro do sistema de avaliação, que de alguma forma sintetizem o diagnóstico de participação em geral do estudante durante o curso, como é o caso do Perfil Dialógico, pode melhorar a sistematização de avaliaçóes formativas em cursos a distância.

Por outro lado, os resultados deste estudo também permitem afirmar que, uma vez que bons índices no Perfil Dialógico corresponderam a bons índices na avaliação final do estudante, pode-se inferir que os sujeitos analisados primaram por uma postura dialógica, segundo Freire (2006a), buscando exercer autonomia (esperança) e, ao mesmo tempo, valorizar a autonomia dos colegas ( $f e ́$ nos homens). Nos debates argumentaram, confrontaram ideias e problematizaram (pensar critico). Em contrapartida, preservaram o respeito mútuo (amor) nas discussóes e não se colocam frente à turma como detentores do saber (humildade), contribuindo para a sua própria aprendizagem como também para uma construçáo colaborativa de novos conhecimentos.

Assim, este mapeamento permite identificar uma forte relação entre a adoção de uma linha educacional progressista, marcada por princípios éticos, de disposição à colaboração, à criticidade e à reflexão, com um resultado satisfatório no curso. Contribui, portanto, para um avanço em relação às pesquisas discutidas neste artigo (BASSANI; BEHAR, 2006; PRETI 2008; OLIVEIRA, 2012), demonstrando a importância de se observar o contexto dialógico no processo de análise das interaçóes, fundamentais ao desenvolvimento de avaliaçôes formativas. A inclusão do Perfil Dialógico como parâmetro de avaliação em cursos de formação online de professorestutores, demonstra uma contribuição de Freire (2006a, 2006b) para a EaD. Aponta a avaliação como um processo integrado às açôes educacionais, podendo favorecer o aprendizado dos educandos.

Logo, o Perfil Dialógico constitui um parâmetro relevante para auxiliar professores-tutores a desenvolverem sua prática avaliativa, não somente no acompanhamento individual dos estudantes, mas também na construção de um cenário dialógico que favorecerá o desenvolvimento individual e coletivo. 


\section{Conclusões}

Esta pesquisa teve como objetivo apresentar os pilares do diálogo freireano como elementos importantes a serem considerados na avaliação da aprendizagem em cursos a distância. Tais pilares foram transformados em critérios (Perfil Dialógico) e incorporados no sistema de avaliação de um curso voltado para professores-tutores em formação. A análise da relação entre os escores obtidos no curso e o Perfil Dialógico dos alunos ressaltou a relevância da pedagogia progressista de Paulo Freire. O Perfil Dialógico confirma o posicionamento de Freire (2007) de que o saber deve ser concebido numa perspectiva dinâmica, em constante transformação e dependente de uma visáo totalizada do contexto.

A avaliação do Perfil Dialógico revelou que os estudantes buscaram atingir os indicadores de uma postura interativa, contribuindo autonomamente com as colocaçôes dos demais participantes, promovendo a reflexão, a negociação de significados, e, acima de tudo, respeitando o posicionamento do outro. Essa prática se aproxima do pensamento de Freire (2006a), ao defender que em cenários problematizadores os estudantes, autonomamente, compartilham suas experiências, resolvem problemas em conjunto e, consequentemente, vivenciam momentos de crescimento e aprendizado coletivos.

Assim, embora já se demonstre uma preocupação com a avaliação formativa em cursos a distância (BASSANI; BEHAR, 2006: PRETI, 2008; OLIVEIRA, 2012), fazse necessário considerar referenciais teóricos como o de Paulo Freire. Os dados deste estudo revelaram que a análise da postura dialógica dos participantes durante o curso, em forma de critérios sistematizados no sistema de avaliação, influenciou-os positivamente. Espera-se que esses critérios possam colaborar na criação de indicadores que favoreçam a implementação de avaliações de caráter formativo em cursos de formação online de professores-tutores.

As próximas pesquisas devem investigar como os tutores-formadores de cursos a distância voltados para professores-tutores avaliam seus estudantes dentro de uma esfera dialógica, acompanhando seus progressos e dificuldades. Deve-se compreender melhor como esses dados podem ajudá-los a reorientarem sua prática pedagógica e ampliarem seu olhar por meio de sistemas avaliativos diversos.

\section{Nota}

${ }^{1}$ Disponível em: <http://www.solar.virtual.ufc.br>. 


\section{REFERÊNCIAS}

BASSANI, Patrícia S.; BEHAR, Patrícia Alejandra. Uma proposta para avaliação da aprendizagem em ambientes de educação à distância. In: CONGRESSO IBEROAMERICANO DE INFORMÁTICA EDUCATIVA, 8., 2006, San José. Anais... Costa Rica: Universidade Nacional de Costa Rica, 2006.

BARBOSA, Jane Rangel Alves. A avaliação da aprendizagem como processo interativo: um desafio para o educador. Democratizar, Rio de Janeiro, v. 2, n. 1, jan./abr. 2008.

BOTH, Ivo José. Ensinar e avaliar são de domínio público: resta saber se ensinar avaliando e avaliar ensinando também o são. HISTEDBR, Campinas, n. 18, p. 5464, jun. 2005.

CALDEIRA, Ana Cristina M. Avaliação da aprendizagem em meios digitais: novos contextos. In: CONGRESSO INTERNACIONAL DE EDUCAÇÃO A DISTÂNCIA, 11., 2004, Salvador. Anais... Salvador: ABED, 2004. Disponível em: <http://www.abed.org.br/congresso2004/por/htm/033-TC-A4.htm>. Acesso em: 10 dez. 2012.

CERNY, Roseli Zen; ERN, Edel. Uma reflexão sobre a avaliação formativa na educação a distância. Salvador: UFBA, 2001. Disponível em:

<http://www.universidadenova.ufba.br/twiki/pub/GEC/TrabalhoAno2001/uma_refl exao_sobre_a_avaliacao_formativa_na_ead.pdf>. Acesso em: 10 dez. 2012.

CUPOLILlO, Amparo V. Avaliação da aprendizagem escolar e o pensamento de Paulo Freire: algumas aproximaçóes. Práxis Educativa, Ponta Grossa, v. 2, n. 1, p. 51-64, jan./jun. 2007.

DAVID, Priscila Barros. Interaçóes contingentes em ambientes virtuais de aprendizagem. 2010. 226f. Tese (Doutorado em Educação Brasileira) - Universidade Federal do Ceará, Fortaleza, 2010.

DAVID, Priscila B. et al. Avaliação da aprendizagem em educação a distância numa perspectiva sócio-interacionista. In: SIMPÓSIO BRASILEIRO DE INFORMÁTICA NA EDUCAÇÃO, 18., 2007, São Paulo. Anais... São Paulo: SBC, 2007.

FREIRE, Paulo. Extensão ou comunicação? Rio de Janeiro: Paz e Terra, 1982.

FREIRE, Paulo. Pedagogia do oprimido. Rio de Janeiro: Paz e Terra, 2006 . 
FREIRE, Paulo. Pedagogia da esperança: um reencontro com a Pedagogia do Oprimido. Rio de Janeiro: Paz e Terra, 2006b.

FREIRE, Paulo. Pedagogia da autonomia: saberes necessários à prática educativa. 33. ed. Rio de Janeiro: Paz e Terra, 2007.

FREIRE, Paulo. Educação e Mudança. 31. ed. São Paulo: Paz e Terra, 2008.

HADJI, Charles. Avaliação desmistificada. Tradução de Patrícia Ramos. Porto Alegre: Artes Médicas, 2001.

HAYDT, Regina C. Avaliação do processo ensino-aprendizagem. São Paulo: Ática, 2002.

LUCKESI, Cipriano C. Verificação ou Avaliação: o que pratica a escola? In:

LUCKESI, Cipriano C. Avaliação da aprendizagem escolar: estudos e proposiçóes.

São Paulo: Cortez, 2008. p. 85-101.

OLIVEIRA, Hélio. Avaliação formativa da aprendizagem em fóruns virtuais. In:

SIMPÓSIO INTERNACIONAL DE EDUCAÇĀO A DISTÂNCIA, 1., 2012, São Carlos. Anais... São Carlos: SIED, 2012. Disponível em:

$<$ http://sistemas3.sead.ufscar.br/ojs/Trabalhos/307-986-1-ED.pdf>. Acesso: 5 maio 2013.

OTSUKA, Joice L.; ROCHA, Heloísa V. Avaliação formativa em ambientes de EaD. In: SIMPÓSIO BRASILEIRO DE INFORMÁTICA NA EDUCAÇÃO, 8., 2002, São Leopoldo. Anais... São Leopoldo: SBIE, 2002.

PRETI, Oresti. Avaliaçáo da aprendizagem em cursos a distância: delegando responsabilidade aos tutores. In: SERRA, Antonio Roberto Coelho; SILVA, João Augusto Ramos (Org.). Por uma Educação sem Distância: recortes da realidade brasileira. 1. ed. São Luis, MA: EDUEMA, 2008. v. 1. p. 185-198.

PERRENOUD, Philippe. Avaliaçâo: da excelência à regulação das aprendizagens entre duas lógicas. Porto Alegre: Artes Médicas, 1999.

PIAGET, Jean. Estudos Sociológicos. Rio de Janeiro: Forense, 1973.

POLAK, Ymiracy N. S. Avaliação do aprendiz em EAD. In: LITTO, Fredric M.; FORMIGA, Marco. Educação a distância: o estado da arte. São Paulo: Pearson do Brasil, 2009. p.153-159.

RIOS, Mônica P. G. A avaliação formativa como procedimento de qualificação docente. E-Curriculum, São Paulo, v. 1, n. 1, jan./jul. 2006. 
SILVA, Marco (Org.). Educação online. 2. ed. São Paulo: Loyola, 2006.

SCHLEMMER, Eliane. Metodologias para educação a distância no contexto da formação de comunidades virtuais de aprendizagem. In: BARBOSA, Rommel Melgaço (Org.). Ambientes virtuais de aprendizagem. Porto Alegre: Artmed, 2005. p. 29-49.

VILLARRUEL-FUENTES, Manuel. Evaluación educativa: elementos para su diseño dentro del aula. Revista Iberoamericana de Educación, Madrid, 2003. Disponível em: <http://www.rieoei.org/deloslectores/473Villarruel.pdf>. Acesso em: 21 abr. 2014. 


\section{The dialogical profile as an evaluation criterion in online tutors training}

\section{Abstract}

This paper analyzes the relationship between the willingness to dialogue and the utilization rate of tutors-teachers participants of a training course offered in an online professional development course. The research aimed to investigate the inclusion of Paulo Freire's dialog pillars as additional criteria in the course's evaluation learning system, allowing the performance of formative assessments. The study consisted of two general steps: the transformation of the pillars of the dialogue in evaluation criteria and their application in the assessment of student learning. The grouping of such criteria was named Dialogic Profile, which was organized based on Paulo Freire's theoretical framework and on empirical studies based on it, which analyze interactive processes in distance education courses. The study was conducted with 29 teachers-tutors and their tutor-trainer. The Dialogic Profile allowed the observation of the students' participation in all course activities, considering mainly the social relationships they developed. Results point to the alignment between the primacy for dialogical contexts and the satisfactory rate of tutors in professional development online courses.

Keywords: Teachers Training. Learning Evaluation. Online Education.

\section{El perfil dialógico como criterio de evaluación en la formación online de profesores tutores}

\section{Resumen}

En este artículo se analiza la relación entre la disposición al diálogo y el nivel de logro de los profesores/tutores que participan de un curso de formación ofrecido en la modalidad de educación a distancia. La investigación tuvo como objetivo investigar la inclusión de los pilares del diálogo freireano como criterios adicionales en el sistema de evaluación de aprendizaje del curso, viabilizando realizar evaluaciones formativas. El estudio consistió en dos pasos generales: la transformación de los pilares del diálogo en los criterios de evaluación y su aplicación en la evaluación del aprendizaje de los estudiantes. El agrupamiento de estos criterios fue denominado de Perfil Dialógico, construido sobre la base de los estudios teóricos de Paulo Freire y en estudios empíricos basados en él, que analizan los procesos interactivos en cursos en esta modalidad. La investigación contó con la participación de 29 estudiantes en formación y un tutor. El Perfil Dialógico permitió observar las acciones de los estudiantes en todas las actividades del curso, teniendo en cuenta, sobre todo, las relaciones por ellos desarrolladas. Los resultados indican un acuerdo entre la primacía de los contextos dialógicos y una satisfacción en los cursos para la formación de los profesores.

Palabras claves: Formación de Profesores. Evaluación del Aprendizaje. Educación a Distancia. 
Priscila Barros David

E-mail:priscila@virtual.ufc.br

\section{Raquel Santiago Freire}

E-mail: freire@virtual.ufc.br

Paula Patrícia Barbosa Ventura

E-mail:profavirtual@gmail.com

Recebido em: 29/5/2013

Aprovado em: 8/4/2014 